\title{
Privatizing funding for maternal, child health
}

$\mathrm{F}$ irst, the federal government radically reset Canadian foreign aid strategies to focus on maternal and child health projects. Now, it is transforming how those projects - traditionally managed on a not-for-profit basis - are financed.

The field is now open to private sector investors, Christian Paradis, Minister of International Development, emphasized during a webinar with medical researchers from Montréal, Toronto and Vancouver on Nov. 14.

That message was also delivered to a meeting of some 80 international development groups convened by the Canadian Network for Maternal Newborn and Child Health (CAN-MNCH) on Nov. 5 - a meeting that was closed to media.

Government officials are fashioning "a new financing paradigm" for maternal and child health based on forging "public-private partnerships" with corporations aiming to finance, and profit from, maternal and child survival programs, says Hieu "Tom" Bui, director, Prosperity and Development, with the Department of Foreign Affairs International Trade and Development.

That paradigm actually began in 2011, when the federal government earmarked development funds for projects co-financed by Canadian mining companies in regions with high maternal and child mortality

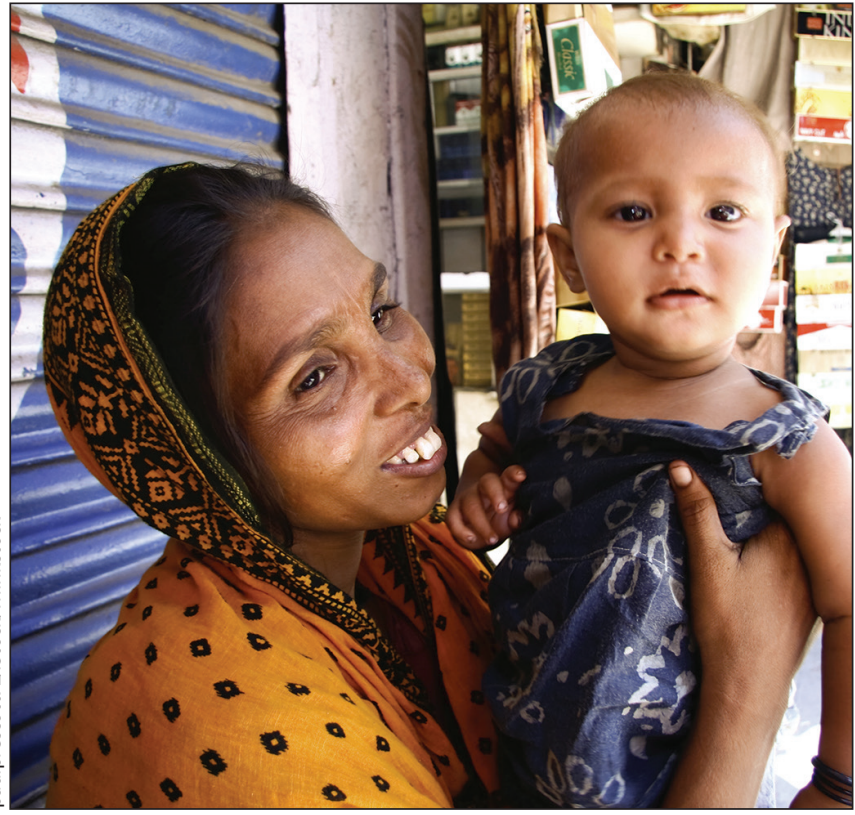

"International development is being redefined by this government as economic development," says one critic of the recent movement toward increased private funding.

Bui says Canada now leads efforts internationally to inject private capital into maternal and child health projects. Paradis chairs a new Redesigning Development Finance Initiative, coordinated by the World Economic Forum and the Organisation for Economic Co-operation and Development. Its aim is "to extend the reach and effectiveness of private investment" alongside publicly funded development programs.

There are several other private-public projects now underway. Grand Challenges Canada has invested $\$ 158$ million in more than 80 countries and attracted $\$ 224$ million in additional funding from outside the Government of Canada, including significant private sector investment. Jocelyn Mackie, vice president,
Operations, says "these problems are too great for governments alone to solve.'

Merck for Mothers, has received $\$ 500$ million from Merck \& Co. to improve the health and well-being of mothers during pregnancy and childbirth. Executive Director Priya Agrawal says the Canadian government's drive to forge corporate financing within its maternal and child health programs is part of a growing international movement.

However, not all observers are convinced that encouraging profit-oriented entities to finance maternal and child survival programs is advisable.

"International development is being redefined by this government as economic development," says Arne Ruckert, a development financing analyst at the University of Ottawa's Institute of Population Health. "And that is paving the way for the use of development funds as subsidies for Canadian corporations. We're seeing the financialization of global health as a profit-based industrial sector."

Ruckert says corporations that invest in development partnerships have an increased ability to "influence policy making at both the global and national level, and bring direct financial returns, such as tax breaks and market penetration, as well as direct financial benefits through brand and image promotion." - Paul Webster, Toronto, Ont.

CMAJ 2015. DOI:10.1503/cmaj.109-4951 